\title{
Epidemiology, clinical features, and management of severe hypercalcemia in critically ill patients
}

\author{
Cyril Mousseaux ${ }^{1 *}$, Axelle Dupont ${ }^{2}$, Cédric Rafat ${ }^{3}$, Kenneth Ekpe $^{1}$, Etienne Ghrenassia', Lionel Kerhuel ${ }^{1}$, \\ Fanny Ardisson ${ }^{1}$, Eric Mariotte ${ }^{1}$, Virginie Lemiale ${ }^{1}$, Benoît Schlemmer ${ }^{1}$, Elie Azoulay ${ }^{1}$ and Lara Zafrani ${ }^{1}$
}

\begin{abstract}
Background: Severe hypercalcemia (HCM) is a common reason for admission in intensive-care unit (ICU). This case series aims to describe the clinical and biological features, etiologies, treatments, and outcome associated with severe HCM. This study included all patients with a total calcemia above $12 \mathrm{mg} / \mathrm{dL}(3 \mathrm{mmol} / \mathrm{L})$ admitted in two ICUs from January 2007 to February 2017.

Results: 131 patients with HCM were included. HCM was related to hematologic malignancy in 58 (44.3\%), solid tumors in 29 (22.1\%), endocrinopathies in 16 (12.2\%), and other causes in 28 (21.3\%) patients. 108 (82.4\%) patients fulfilled acute kidney injury (AKI) criteria. Among them, 25 (19\%) patients required renal replacement therapy (RRT). 51 (38.9\%) patients presented with neurological symptoms, 73 (55.7\%) patients had cardiovascular manifestations, and 50 (38.1\%) patients had digestive manifestations. The use of bisphosphonates ( $\mathrm{HR}, 0.42 ; 95 \% \mathrm{Cl}, 0.27-0.67 ; \mathrm{P}<0.001$ ) was the only treatment significantly associated with a decrease of total calcemia below $12 \mathrm{mg} / \mathrm{dL}(3 \mathrm{mmol} / \mathrm{L})$ at day 5. ICU and Hospital mortality rates were, respectively, $9.9 \%$ and 21.3\%. Simplified Acute Physiologic Score (SAPS II) (OR, $1.05 ; 95 \% \mathrm{Cl} 1.01-1.1 ; P=0.03)$ and an underlying solid tumor $(\mathrm{OR}, 13.83 ; 95 \% \mathrm{Cl} 2.24-141.25 ; P=0.01)$ were two independent factors associated with hospital mortality in multivariate analysis.

Conclusions: HCM is associated with high mortality rates, mainly due to underlying malignancies. The course of HCM may be complicated by organ failures which are most of the time reversible with early ICU management. Early ICU admission and prompt HCM management are crucial, especially in patients with an underlying solid tumor presenting with neurological symptoms.
\end{abstract}

Keywords: Hypercalcemia (HCM), Onco-hematology, Acute kidney injury (AKI), AKI etiology, Renal replacement therapy (RRT), Kidney disease outcome, Prognosis, Mortality

\section{Background}

Hypercalcemia (HCM) is commonly defined by a serum calcium level above $2.6 \mathrm{mmol} / \mathrm{L}$ or $10.5 \mathrm{mg} / \mathrm{dL}, 40 \%$ of which is ionized calcium [1]. Despite the lack of a clear definition of a severe HCM, a calcemia above $12 \mathrm{mg} / \mathrm{dL}$ $(3 \mathrm{mmol} / \mathrm{L})$ is frequently retained.

Because HCM may lead to life-threatening complications, patients often require Intensive-Care Unit (ICU)

\footnotetext{
*Correspondence: mousseaux.cyril@gmail.com

${ }^{1}$ Medical Intensive Care Unit, Saint-Louis Hospital, Assistance

Publique-Hopitaux de Paris, Paris Diderot University, Paris, France

Full list of author information is available at the end of the article
}

admission. Clinical symptoms are non-specific, depending on calcium levels and rapidity of onset. They include renal complications, ranging from polyuria to acute kidney injury (AKI) [2]; cardiovascular complications, including sinus tachycardia, hypertension, and infarctlike ST segment elevation [3]; digestive events, from abdominal pain to acute pancreatitis [4], and neurological impairments, including seizures [5], delirium, and coma.

Epidemiological data focusing on HCM in ICU are scarce. In a multicentric retrospective study, severe hypercalcemia (defined by a ionized calcemia $>2.9 \mathrm{mEq} / \mathrm{L}$ 
or $1.45 \mathrm{mmol} / \mathrm{L}$ ) occurred in $2 \%$ of critically ill patients [6]. Few studies found an independent association between HCM and hospital or ICU mortality [7, 8].

Among all causes of HCM, primary hyperparathyroidism and malignancies (including solids tumor and hematologic malignancies) are predominant. Recent epidemiological studies estimate that HCM affects between 0.65 and $3 \%$ of all oncology patients $[9,10]$. Within tumor-related etiologies, multiple myeloma, breast, lung, and kidney cancers are the most frequent. In this context, HCM often occurs at a metastatic stage [9], which is no more per se a contraindication for ICU admission [11, 12]. However, there are no data available on etiologies responsible for HCM in ICU patients.

Due to the scarcity of epidemiological and clinical data of patients suffering from HCM in ICU, we conducted a retrospective study of 131 patients in two different French ICUs. Our objectives were to characterize clinical and biological features of $\mathrm{HCM}$, to identify risk factors for complications of HCM and risk factors of mortality.

\section{Methods}

This present work is a retrospective study performed in two distinct ICUs. The medical ICU of the Saint-Louis University Hospital, Paris, France, is a 12-bed medical unit that admits 850 patients per year, of whom about one-third have hematologic malignancies. The nephrology ICU of the Tenon University Hospital, Paris, France is a 17-bed medical unit that admits 900 patients per year. The study was approved by the ethical committee of the "Société de reanimation de langue française" ( $\left.{ }^{\circ} 18-34\right)$.

\section{Patients}

We included all adult patients admitted in ICU with severe HCM from January 2007 through February 2017. We defined severe HCM by a total calcemia above $12 \mathrm{mg} /$ $\mathrm{dL}(3 \mathrm{mmol} / \mathrm{L})[13,14]$. When needed, calcemia was corrected by serum albumin level, and in default of, by total protein levels.

\section{Definitions}

Definition and staging of AKI were defined according to the 2012 KDIGO (Kidney Disease: Improving Global Outcomes) guideline [15]. Decisions regarding the initiation, discontinuation, and modalities of renal replacement therapy (RRT) were made by senior nephrologists based on the guidelines from Bellomo and Ronco [16].

Etiologies of HCM were retrospectively subdivided in four groups: (1) hematologic malignancies; (2) solid tumors; (3) endocrinopathies; (4) other causes, including iatrogenic, granulomatosis, and unknown causes. We sought for etiological investigations including the testing of PTH or 1-25(OH) Vit D during the hospital stay.
Based on known complications of HCM [1, 17], we classified HCM manifestations in four entities: (1) renal manifestations, including polyuria and acute kidney injury; (2) cardiovascular manifestations, including de novo arterial hypertension and any EKG manifestations; (3) neurological manifestations, including seizures and mental status alteration; and (4) digestive manifestations, such as acute pancreatitis, digestive occlusion, or constipation.

We used the Glasgow scale score [18] for evaluation of mental status at admission.

Bisphosphonate safety was assessed on creatinine variation 3 months after admission in ICU.

\section{Patient's characteristics}

Demographic parameters, medical history, presenting symptoms, and treatments were collected. All laboratory data were recorded at admission. Serum creatinine level was recorded 3 months before ICU admission when possible, at ICU admission, ICU discharge, hospital discharge, 3 and 6 months after ICU and at last follow-up. Sequential Organ Failure Assessment (SOFA) and Simplified Acute Physiology Score (SAPS II) parameters were collected on day $1[19,20]$. ECOG/ WHO performance status [21], and Charlson comorbidity index [22] were evaluated based on precedent medical records.

Serum PTH level were measured using a radioimmunologic assay (CIS-Bio-Radio-ImmunoAnalysis ${ }^{\circledR}$ ) with a normal range between 8 and $76 \mathrm{ng} / \mathrm{L}$. Serum 25-dihydroxyvitamin D was measured using a radioimmunologic method (Diasorin ${ }^{\circledR}$ ) that recognized both 25-hydroxyvitamin D2 and 25-hydroxyvitamin D3. An excess of 25-dihydroxyvitamin D was arbitrary defined by a level above $100 \mathrm{ng} / \mathrm{mL}$. Serum 1,25-dihydroxyvitamin D was measured using a radio-immunologic method $\left(\right.$ Diasorin ${ }^{\circledR}$ ) with reference values ranging from 20 to $60 \mathrm{pg} / \mathrm{mL}$. Plasma phosphate was measured using colorimetry (phosphomolybdate assay) and serum ionized calcium, using a specific electrode.

Vital status at ICU discharge, hospital discharge, and last follow-up were determined from medical records and the outpatient clinic electronic database.

\section{Treatment}

All patients received the standard of care. The period and duration of renal replacement therapy were collected. Bisphosphonate treatment dose and duration were recorded. Type and daily volume of hydration, corticosteroid treatment, use of salmon calcitonin, furosemide in hypocalcemic purpose, and calcimimetic were collected. 


\section{Statistical analyses}

Patients' characteristics at ICU admission are described as median and interquartile range (IQR) for quantitative variables and frequencies and percentages for qualitative variables. Distribution of baseline variables, life-supporting treatments, and specific treatments of $\mathrm{HCM}$ were compared between patients alive or not at leaving the ICU using the Wilcoxon test for quantitative variables, and Fisher's test for qualitative variables.

Cumulative incidence of mortality in ICU and hospital was estimated, taking ICU or hospital discharge as competing risk. Univariate analysis for complications was performed in logistic regression to identify factors associated with complications. For mortality risk in ICU, univariate analysis with logistic regression was adjusted on SAPSII scale score and Charlson morbidity index. Multivariate models were adjusted on age, SAPSII for mortality, pre-existing cardiopathy for cardiovascular complications, CKD for AKI stage 3, and variables that were significant at 0.15 level.

The endpoint of treatment analysis was the diminution of total calcemia below $3 \mathrm{mmol} / \mathrm{L}(12 \mathrm{mg} / \mathrm{dL})$ between day 0 and day 5 . Univariate analyses were performed in Cox proportional hazards regression models. Final multivariate model was adjusted on etiologies and significant treatments at 0.15 levels. Patients with stage V-CKD were excluded from this analysis. All tests were two sided with a 5\% type I error. All calculations were performed with the R software (version 3.4.4) ${ }^{\circledR}$.

\section{Results}

Patients' characteristics at ICU admission

During the study period, 131 patients presented with severe hypercalcemia. Patient characteristics at ICU admission are reported in Table 1. Median SOFA score and SAPSII score were 2 (IQR, 1; 4) and 29.5 (IQR, 22; 36.75), respectively. $\mathrm{HCM}$ was related to hematologic malignancies in $58(44.3 \%)$ patients, solid tumors in 29 (22.1\%) patients, endocrinopathies in $16(12.2 \%)$ patients, and other causes in $28(21.3 \%)$ patients. Endocrinopathies were mainly due to primary hyperparathyroidism in 15 (93.7\%) patients. Other causes are detailed in Table 1. Among them, 15 patients had a suspected vitamin D intoxication [14 received $1-25(\mathrm{OH})$ vitamin D and 4 received cholecalciferol for $25(\mathrm{OH})$ vitamin $\mathrm{D}$ supplementation]. In most cases (14/15), patients received additional calcium supplementation. $14 / 15$ patients had a past of thyroidectomy with 7 post-surgery hypoparathyroidism and 1 hypocalcemia of unknown origin. Patients' characteristics with suspected vitamin D intoxication are

Table 1 Patients' demographic and clinical characteristics at admission

\begin{tabular}{|c|c|c|c|c|c|}
\hline & $\begin{array}{l}\text { All } \\
(n=131)\end{array}$ & $\begin{array}{l}\text { Hemopathy } \\
(n=58)\end{array}$ & $\begin{array}{l}\text { Solid tumors } \\
(n=29)\end{array}$ & $\begin{array}{l}\text { Endocrinopathies } \\
(n=16)\end{array}$ & Other $(n=28)$ \\
\hline \multicolumn{6}{|l|}{ Clinical data } \\
\hline Age (y) & $58.5[48.5 ; 69]$ & $58[42 ; 67]$ & $63[52 ; 68]$ & $52[36.5 ; 67.25]$ & $66[55.25 ; 74.25]$ \\
\hline Women, $n(\%)$ & $64(48.8)$ & $22(38)$ & $17(58.6)$ & $9(56)$ & $16(57.1)$ \\
\hline Chronic kidney disease, $n$ (\%) & $25(19.5)$ & $10(17.2)$ & $2(6.8)$ & $4(25)$ & $10(35.7)$ \\
\hline Cardiopathy, n (\%) & $32(25)$ & $8(13.7)$ & $6(20.7)$ & $4(25)$ & $15(53.5)$ \\
\hline SOFA score at day 1 & $2[1,4]$ & $4[2,5]$ & $1[1,3]$ & $1[0 ; 2]$ & $2[1,3]$ \\
\hline SAPS II score at day 1 & $29.5[22 ; 36.75]$ & $34[28,40]$ & $33[24,37]$ & $19.5[16.75 ; 29.25]$ & $27[18.5 ; 33]$ \\
\hline ECOG/WHO scale score & $1[0 ; 3]$ & $1[0 ; 2]$ & $3[1,3]$ & $0.5[0 ; 2.75]$ & $1[0 ; 3]$ \\
\hline Charlson score & $4[2,6]$ & $3[2,4]$ & $7[6,9]$ & $3[1,6]$ & $4[2 ; 6.25]$ \\
\hline \multicolumn{6}{|l|}{ Admission diagnosis in ICU } \\
\hline Hypercalcemia, n (\%) & $101(77.1)$ & $42(72.4)$ & $22(76)$ & $13(81)$ & $23(82)$ \\
\hline Coma, delirium, n (\%) & $9(6.8)$ & $3(5.2)$ & $5(17.2)$ & 0 & $1(3.5)$ \\
\hline $\begin{array}{l}\text { Acute respiratory failure, } \\
n(\%)\end{array}$ & $5(3.8)$ & $4(6.8)$ & $1(3.4)$ & 0 & 0 \\
\hline Tumor lysis syndrome, $n(\%)$ & $4(3)$ & $4(6.8)$ & 0 & 0 & 0 \\
\hline Acute kidney injury, n (\%) & $4(3)$ & $2(3.4)$ & $1(3.4)$ & 0 & $1(3.5)$ \\
\hline Sepsis, $n(\%)$ & $5(3.8)$ & $1(1.7)$ & 0 & $3(19)$ & $1(3.5)$ \\
\hline Other, $n(\%)$ & $3(2.2)$ & $2(3.4)$ & 0 & 0 & $2(7)$ \\
\hline
\end{tabular}

Values for categorical variables are given as number (percentage); values for continuous variables, as median [interquartile range]

Other causes included iatrogenic causes $(n=16 ; 57.1 \%)$, sarcoidosis $(n=4 ; 14.2 \%)$, tuberculosis $(n=1 ; 3.5 \%)$, atypical mycobacterial infection $(n=1 ; 3.5 \%)$, global dehydration $(n=1 ; 3.5 \%)$, and unknown causes $(n=5 ; 17.8 \%)$

ECOG/WHO Eastern Cooperative Oncology Group/World Health Organization, SAPS I/ Simplified Acute Physiology Score, SOFA Sequential Organ Failure Assessment 
summarized in Additional file 1: Table S1. HCM was the main reason for ICU admission in 101 (77.1\%) patients.

\section{Clinical features}

Patients' clinical features are reported in Fig. 1 and renal manifestations are reported in Table 2. Fifteen (11.4\%) patients had polyuria before ICU admission. One hundred and eight (82.4\%) patients fulfilled AKI criteria: stage 1, 37 (34.2\%); stage 2, 30 (27.7\%); and stage 3, 41 (37.9\%). The main presumed diagnoses for AKI were hypoperfusion (63\%), acute tubular necrosis (19\%), cast nephropathy (16\%), obstructive (10\%), and tumor lysis syndrome (7\%). Thirty (23\%) patients presented multiple possible causes of AKI. No patient had a kidney biopsy during ICU stay.

Details of extra-renal manifestations are reported in Additional file 1: Table S2. Fifty-one (38.9\%) patients presented with neurological manifestations, mostly delirium (39 patients representing $29.8 \%$ of the total population). Seventy-three (55.7\%) patients had cardiovascular manifestations. De novo arterial hypertension was noted in $23(17.5 \%)$ patients. The most frequent EKG signs, reread by a trained senior, were sinus tachycardia $(n=31,23.6 \%)$, conduction disturbances $(n=20,15.2 \%)$, and short QT interval $(n=19$, $14.5 \%)$. Fifty $(38.1 \%)$ patients had digestive manifestations including abdominal pain in $26(19.8 \%)$ patients.

\section{Calcemia course}

Characteristics of calcemia levels and etiological investigations are reported in Table 3. Calcemia course between day 1 and day 9 is depicted in Additional file 1: Figure S1. Median total calcemia level at admission was 14.5 (IQR, 13.2; 16.3) mg/dL. Median magnesium level was $0.39 \mathrm{mEq} / \mathrm{L}(\mathrm{IQR}, 0.34 ; 0.43)$ and median natremia was $138 \mathrm{mmol} / \mathrm{L}$ (IQR, 134; 140). Patients with HCM due to endocrinopathies had significative higher PTH median level (460 ng/mL, IQR, 197.5; 589 versus 8.5, IQR: 3.9; 16.25; $\mathrm{P}<0.0001)$. As expected, patients with primary hyperparathyroidism tend to have a lower median level of phosphoremia (2.4, IQR, 1.9; $2.6 \mathrm{mg} / \mathrm{dL}$ versus 3.7, IQR, $2.8 ; 4.9 \mathrm{mg} / \mathrm{dL}, \mathrm{P}<0.0001)$ when compared with other patients. Fifty-two (39.7\%) patients were tested for $1-25(\mathrm{OH})$ vitamin $\mathrm{D}$ with a median level at $16 \mathrm{pg} /$ $\mathrm{mL}$ (IQR, 6.9; 28.3). Twenty-one patients (16\%) had high 1,25-dihydroxyvitamin D levels (above $60 \mathrm{pg} / \mathrm{mL}$ ). Among 65 (49.6\%) patients tested for 25(OH) vitamin $\mathrm{D}$, only $2(3 \%)$ had an intoxication due to massive vitamin D ingestion. Diagnosis of paraneoplastic hypercalcemia with high PTH-rp level was retained in three $(2.3 \%)$ patients.

\section{Treatment characteristics and outcomes}

Treatment characteristics and outcomes are detailed in Table 4.

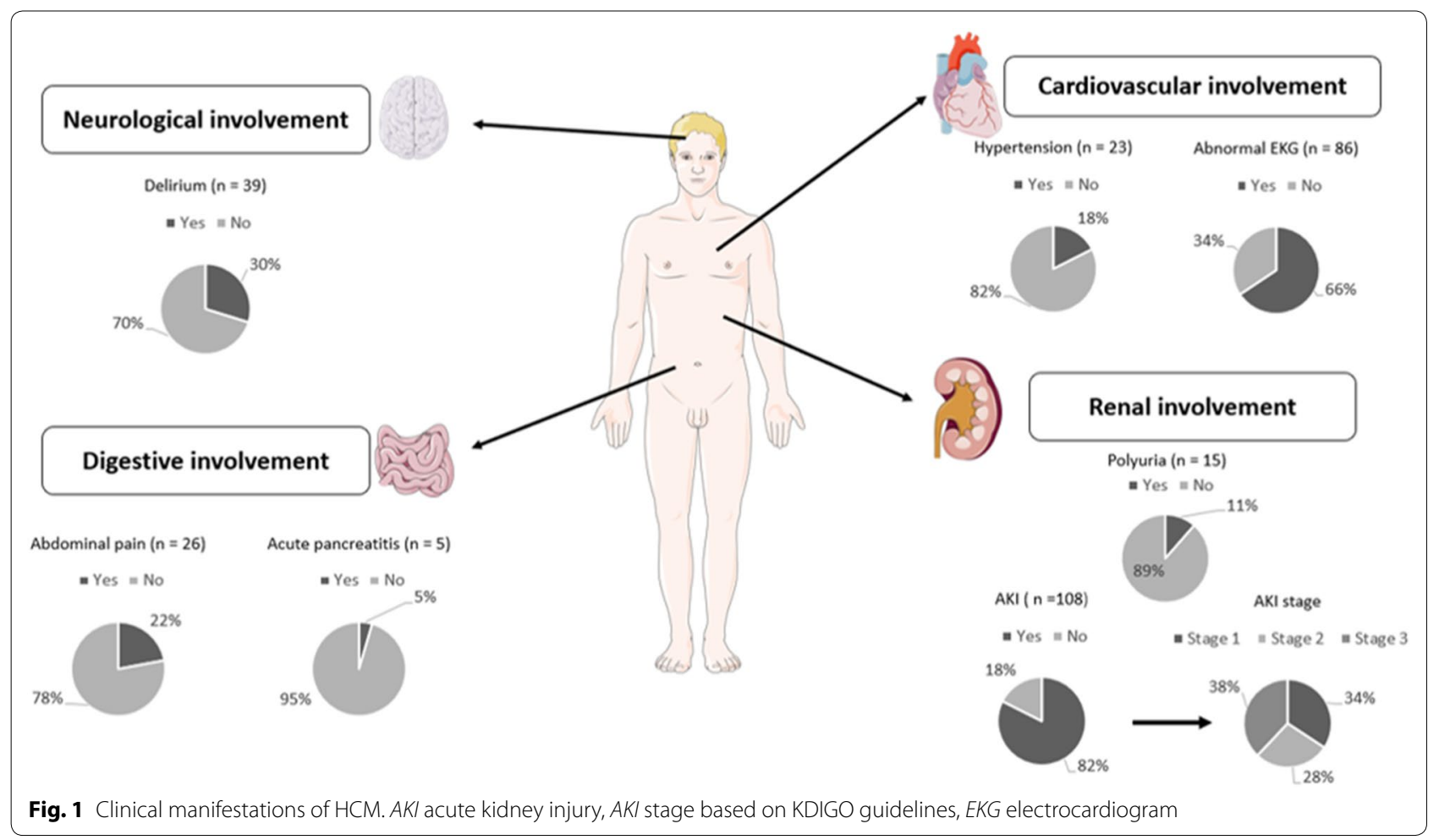


Table 2 Characteristics of AKI

\begin{tabular}{|c|c|}
\hline Variable & Value \\
\hline Scr (mg/dL) 3 months before ICU admission & $0.9[0.7 ; 1.2]$ \\
\hline eGFR $\left(\mathrm{mL} / \mathrm{min} / 1.73 \mathrm{~m}^{2}\right)$ before ICU admission & $85[63 ; 109]$ \\
\hline Polyuria, $n(\%)$ & $15(11.4)$ \\
\hline $\mathrm{AKI}, n(\%)$ & $108(82.4)$ \\
\hline \multicolumn{2}{|l|}{ AKI stage } \\
\hline Stage $1, n(\%)$ & $37(34.2)$ \\
\hline Stage $2, n(\%)$ & $30(27.7)$ \\
\hline Stage $3, n(\%)$ & $41(37.9)$ \\
\hline $\mathrm{Scr}(\mathrm{mg} / \mathrm{dL})$ at ICU admission & $1.88[1.1 ; 3.2]$ \\
\hline $\mathrm{Scr}(\mathrm{mg} / \mathrm{dL})$ at day 3 & $1.5[0.9 ; 2.7]$ \\
\hline $\mathrm{Scr}(\mathrm{mg} / \mathrm{dL})$ at day 5 & $1.4[0.9 ; 2.5]$ \\
\hline $\mathrm{Scr}(\mathrm{mg} / \mathrm{dL})$ at day 7 & $1.3[0.8 ; 2.3]$ \\
\hline Maximal Scr (mg/dL) & $1.95[1.1 ; 3.4]$ \\
\hline $\mathrm{Scr}(\mathrm{mg} / \mathrm{dL})$ at ICU discharge & $1[0.7 ; 1.7]$ \\
\hline RRT during ICU stay & $25(19 \%)$ \\
\hline Duration of RRT (d) & $5[2.5 ; 7]$ \\
\hline \multicolumn{2}{|l|}{ Causes of AKI } \\
\hline Hypoperfusion & $68(63 \%)$ \\
\hline Acute tubular necrosis & $20(19 \%)$ \\
\hline Cast nephropathy & $18(16 \%)$ \\
\hline Obstructive & $11(10 \%)$ \\
\hline Tumor lysis syndrome & $8(7 \%)$ \\
\hline Sarcoidosis & $3(3 \%)$ \\
\hline Nephrotoxic agents & $2(2 \%)$ \\
\hline Kidney infiltration by malignancy & $1(1 \%)$ \\
\hline Amyloidosis & $1(1 \%)$ \\
\hline$>1$ cause & $30(23 \%)$ \\
\hline \multicolumn{2}{|l|}{ Follow-up data } \\
\hline $\mathrm{Scr}(\mathrm{mg} / \mathrm{dL})$ at month 3 in RRT-free patients & $0.9[0.7 ; 1.3]$ \\
\hline eGFR $\left(\mathrm{mL} / \mathrm{min} / 1.73 \mathrm{~m}^{2}\right)$ at month 3 in RRT-free patients & $86[63 ; 109]$ \\
\hline $\mathrm{Scr}(\mathrm{mg} / \mathrm{dL})$ at month 6 in RRT-free patients & $0.9[0.7 ; 1.3]$ \\
\hline eGFR $\left(\mathrm{mL} / \mathrm{min} / 1.73 \mathrm{~m}^{2}\right)$ at month 6 in RRT-free patients & $77[54 ; 96]$ \\
\hline
\end{tabular}

$\mathrm{n}=131$. Percentages values are given based for the 108 patients who presented AKI. Values of categorical variables are given as number (percentage); values for continuous variables, as median [interquartile range]. Conversion factor for Scr in $\mathrm{mg} / \mathrm{dL}$ to $\mu \mathrm{mol} / \mathrm{L}$ is 88.4

$A K I$ acute kidney injury, eGFR estimated glomerular filtration rate based on MDRD formula, ICU intensive-care unit, RRT renal replacement therapy, Scr serum creatinine

Conversion factor: Scr, serum creatinine in $\mathrm{mg} / \mathrm{dL}$ to $\mu \mathrm{mol} / \mathrm{L}, \times 88.4$

One hundred and twenty-four (94.6\%) patients received fluid administration, mainly with crystalloids. The main side effect was pulmonary edema in $11(8.3 \%)$ patients. Bisphosphonates were used in 103 (78.6\%) patients, especially in case of solid tumors and hematologic malignancy. Fifteen patients (14.5\%) received bisphosphonates before ICU admission. Of the 103 patients who received bisphosphonates, 46 received zoledronate $(4 \mathrm{mg}$, IQR,
Table 3 Calcemia course and etiological investigations of patients with hypercalcemia

\begin{tabular}{|c|c|}
\hline & $\begin{array}{l}\text { All } \\
(n=131)\end{array}$ \\
\hline \multicolumn{2}{|l|}{ Calcemia } \\
\hline Calcemia at day 1 (mg/dL) & $14.5[13.2 ; 16.3]$ \\
\hline Corrected calcemia at day 1 (mg/dL) & $15.6[14 ; 17.2]$ \\
\hline lonized calcemia at day 1 (mEq/L) & $3.5[3.1 ; 3.9]$ \\
\hline Minimal etiological screening & $86(65.6)$ \\
\hline PTH: patients tested, $n(\%)$ & $84(64.1)$ \\
\hline PTH median level (ng/mL) & $11[4.9 ; 47.5]$ \\
\hline High PTH, $n(\%)$ & $16(19)$ \\
\hline Low or abnormally normal PTH, $n$ (\%) & $68(81)$ \\
\hline PTH-rp: patients tested, $n$ (\%) & $17(13)$ \\
\hline High PTH-rp, n (\%) & $3(2.3)$ \\
\hline $\begin{array}{l}\text { Active Vitamin D (1,25-dihydroxyvitamin D): patients } \\
\text { tested, } n(\%)\end{array}$ & $52(39.7)$ \\
\hline Active Vitamin D (1,25-dihydroxyvitamin D) (pg/mL) & $16[6.9 ; 28.3]$ \\
\hline $\begin{array}{l}\text { High active Vitamin D (1,25-dihydroxyvitamin D) levels, } \\
n(\%)\end{array}$ & $21(16)$ \\
\hline $\begin{array}{l}\text { Vitamin D (25-dihydroxyvitamin D): patients tested, } n \\
(\%)\end{array}$ & 65 (49.6) \\
\hline Vitamin D (25-dihydroxyvitamin D) (ng/mL) & $9.3[5.8 ; 13.6]$ \\
\hline High Vitamin D (25-dihydroxyvitamin D) levels, $n(\%)$ & $2(1.5)$ \\
\hline Phosphatemia at admission (mg/dL) & $3.5[2.6 ; 4.9]$ \\
\hline
\end{tabular}

Values for categorical variables are given as number (percentage); values for continuous variables, as median [interquartile range]

Conversion factors: active Vitamin D (1,25-dihydroxyvitamin D) pg/mL for $\mathrm{pmoL} / \mathrm{L}, \times 2.6$, Vitamin $\mathrm{D}$ (25-dihydroxyvitamin $\mathrm{D}$ ) $\mathrm{ng} / \mathrm{mL}$ for $\mathrm{nmol} / \mathrm{L}, \times 2.496$, total calcemia in $\mathrm{mg} / \mathrm{dL}$ for $\mathrm{mmol} / \mathrm{L}, \times 0.2495$, calcium ion in $\mathrm{mEq} / \mathrm{L}$ for $\mathrm{mmol} / \mathrm{L}$, $\times 0.5$, phosphorus in $\mathrm{mg} / \mathrm{dL}$ for $\mathrm{mmol} / \mathrm{L}, \times 0.3229$

Normal range: PTH: between 5 and $60 \mathrm{pg} / \mathrm{mL}$

PTH parathyroid hormone, $P T H-r p$ parathyroid hormone-related protein

4; 4), 47 patients received pamidronate (90 $\mathrm{mg}$, IQR, 60; 90 ), and 6 patients received ibandronate ( $2 \mathrm{mg}$, IQR, 2; $3.5)$. Only $13(10 \%)$ patients required a second infusion of bisphosphonates. Corticosteroids were administered in $65(50 \%)$ patients. Most of them had an underlying hematologic malignancy ( $84.4 \%$ of the total). Only 13 (10\%) patients received furosemide and 12 (9\%) patients received calcitonin. No patient received denosumab. Twenty-five (19\% of the total population and $23.1 \%$ of the population with AKI) patients needed RRT during their ICU stay. The median duration time was 5 days (IQR, 2.5 ; 7). Tumor lysis syndrome was the main indication for dialysis in 11 (8.4\%) patients, followed by hypercalcemia in $6(4.6 \%)$ patients and pulmonary edema in $4(3 \%)$ patients. Vasopressors were used in $6(4.5 \%)$ patients and mechanical ventilation needed in $10(7.6 \%)$ patients. ICU mortality and hospital mortality rate were $9.9 \%$ and $21.3 \%$, respectively. 
Table 4 Treatment's characteristics and outcomes

\begin{tabular}{|c|c|c|c|c|c|}
\hline & $\begin{array}{l}\text { All } \\
(n=131)\end{array}$ & $\begin{array}{l}\text { Hemopathy } \\
(n=58)\end{array}$ & $\begin{array}{l}\text { Solid tumors } \\
(n=29)\end{array}$ & $\begin{array}{l}\text { Endocrinopathies } \\
(n=16)\end{array}$ & Other $(n=28)$ \\
\hline Hyperhydration, $n$ (\%) & $124(94.6)$ & $53(91.3)$ & $29(100)$ & $16(100)$ & $26(92.8)$ \\
\hline Crystalloid, $n(\%)$ & $119(90)$ & $50(87.7)$ & $29(100)$ & $16(100)$ & $24(85.7)$ \\
\hline Volume at day 1 (L/day) & $3[2,3]$ & $3[2,3]$ & $3[2.5 ; 3]$ & $3.25[2.25 ; 4]$ & $2[2,3]$ \\
\hline Side effect: pulmonary edema, $n(\%)$ & $11(8.3)$ & $9(17)$ & $2(6.8)$ & 0 & 0 \\
\hline Bisphosphonate infusion, $n(\%)$ & $103(78.6)$ & $49(84)$ & $26(89.6)$ & $12(75)$ & $17(60.7)$ \\
\hline Second infusion, $n(\%)$ & $13(10)$ & $5(10.2)$ & $5(19.2)$ & 0 & $3(10.7)$ \\
\hline Corticosteroids, $n(\%)$ & $65(50)$ & $49(84.4)$ & $10(34.5)$ & 0 & $6(21.4)$ \\
\hline Furosemide, $n(\%)$ & $13(10)$ & $6(10.3)$ & $1(3.4)$ & 0 & $6(21.4)$ \\
\hline Calcimimetics, $n(\%)$ & $6(5)$ & 0 & $1(3.4)$ & $5(31)$ & 0 \\
\hline Calcitonin, $n(\%)$ & $12(9)$ & $4(6.8)$ & $5(17.2)$ & $1(6.3)$ & $2(7.1)$ \\
\hline Renal replacement therapy, n (\%) & $25(19)$ & $20(34.4)$ & $3(10.3)$ & $1(6.3)$ & $1(3.6)$ \\
\hline Duration of RRT (d) & $5[2.5 ; 7]$ & $5[2.5 ; 6]$ & 3 & 3 & 11 \\
\hline Vasopressor, n (\%) & $6(4.5)$ & $5(8.6)$ & 0 & 0 & $1(3.5)$ \\
\hline Mechanical ventilation, $n(\%)$ & $10(7.6)$ & $6(10.3)$ & $3(10.3)$ & 0 & $1(3.5)$ \\
\hline ICU mortality, n (\%) & $13(9.9)$ & $4(6.8)$ & $6(20.6)$ & $1(6.3)$ & $2(7.1)$ \\
\hline Hospital mortality, n \%) & $26(21.3)$ & $10(17.2)$ & $13(44.8)$ & $1(6.3)$ & $2(7.1)$ \\
\hline
\end{tabular}

Values for categorical variables are given as number (percentage); values for continuous variables, as median [interquartile range]

ICU intensive-care unit, RRT renal replacement therapy

\section{Risk factors for hypercalcemia-induced complications}

Univariate analysis of risk factors associated with hypercalcemia-induced complications is shown in Additional file 1: Table 3. By multivariate analysis (Table 5), male sex (OR, 0.38; 95\% CI $0.17-0.83 ; P=0.02$ ) was less associated with cardiovascular complications. Two factors were associated independently with neurological complications by multivariate analysis: total calcemia at day 1 (OR, 2; 95\% CI 1.06-3.99; $P=0.04$ ) and underlying solid malignancy (OR, 10.6; 95\% CI 3.16-40.84; $P<0.01$ ).

\section{Impact of HCM on mortality}

Figure 2 is the cumulative incidence curve of hospital mortality based on solid tumor etiology. In univariate analysis (Additional file 1: Table S3) adjusted for SAPSII scale score and Charlson morbidity index, solid tumors and neurological complications were associated with higher hospital mortality. We did not found an association between hospital mortality and bisphosphonate administration. Two factors were independently associated with higher mortality in multivariate analysis (Table 6): SAPSII scale score (OR, 1.05; 95\% CI 1.01-1.1; $P=0.03)$ and underlying solid malignancy (OR, 13.83; 95\% CI 2.24-141.25; $P=0.01)$.

\section{Impact of treatment}

We next analyzed the effectiveness of therapies (i.e., bisphosphonates, corticosteroids, furosemide, and calcitonin) to decrease hypercalcemia below $12 \mathrm{mg} / \mathrm{dL}$ $(3 \mathrm{mmol} / \mathrm{L})$ at day 5 (Additional file 1: Table 4). The use of bisphosphonates (HR, 0.42; 95\% IC, 0.27-0.67; $P<0.001$ ) was the only treatment significantly associated with a decrease of total calcemia below $12 \mathrm{mg} / \mathrm{dL}(3 \mathrm{mmol} / \mathrm{L})$ at day 5 . No difference was observed between ibandronate $(\mathrm{HR}=0.79 ; \quad \mathrm{IQR}=[0.31-2.02], \mathrm{p}=0.62)$, pamidronate $(\mathrm{HR}=0.71 ; \mathrm{IQR}=[0.45-1.14], \mathrm{p}=0.16)$, and zoledronate. We did not found any association between worsened renal function at 3 months with bisphosphonates administration $(p=0.25)$. Twelve patients did not received bisphosphonates with a median creatinine variation of -17 (IQR 25-75 [-55; +10.75]). Thirty-five patients received bisphosphonates with a median creatinine variation of -51 (IQR 25-75 [-139; +2.5]).

\section{Discussion}

The present study is the first to describe etiological investigations and clinical course of ICU patients hospitalized for severe HCM. Indeed, previous studies have focused on the association between ionized calcemia and ICU mortality. Egi et al. [6] found an association between severe HCM and ICU mortality. Conversely, Zhang et al. [23] in a large multicentric cohort did not confirm this association. Beyond these epidemiological studies, there are no data focusing on clinical and biological characterization of these patients.

During HCM, one of the main reasons for ICU admission is the risk of cardiac rhythm disorders and 
Table 5 Multivariate analysis of determinants of HCM complications

\begin{tabular}{|c|c|c|}
\hline & OR $(95 \%$ IC) & $P$ value \\
\hline \multicolumn{3}{|c|}{ Associated factors with cardiovascular complications } \\
\hline Age $>60$ years & $2.05(0.96 ; 4.5)$ & 0.07 \\
\hline Male sex & $0.36(0.16 ; 0.75)$ & 0.01 \\
\hline Pre-existing cardiopathy & $0.63(0.26 ; 1.5)$ & 0.3 \\
\hline Calcemia at day 1 & $1.68(0.93 ; 3.32)$ & 0.11 \\
\hline \multicolumn{3}{|c|}{ Associated factors with neurological complications } \\
\hline Age $>60$ years & $1.89(0.84 ; 4.41)$ & 0.13 \\
\hline Calcemia at day 1 & $2(1.06 ; 3.99)$ & 0.04 \\
\hline \multicolumn{3}{|l|}{ Etiologies } \\
\hline Other & 1 & \\
\hline Hemopathies & $2.48(0.87 ; 7.9)$ & 0.1 \\
\hline Solid tumors & $10.58(3.16 ; 40.84)$ & $<0.01$ \\
\hline Endocrinopathies & $0.6(0.08 ; 3.16)$ & 0.58 \\
\hline \multicolumn{3}{|l|}{ Associated factors with AKI stage $>2^{a}$} \\
\hline Age $>60$ years & $0.3(0.05 ; 1.65)$ & 0.18 \\
\hline \multicolumn{3}{|l|}{ Etiologies } \\
\hline Hemopathies & 1 & \\
\hline Solid tumors & $0.14(0.013 ; 1.63)$ & 0.12 \\
\hline Endocrinopathies and other causes & $0.1(0.009 ; 1.1)$ & 0.06 \\
\hline Chronic kidney disease & $1.31(0.27 ; 6.37)$ & 0.74 \\
\hline
\end{tabular}

a Three patients were excluded due to pre-existing renal replacement therapy

$A K I$ acute kidney injury

Brugada-like electrocardiographic pattern. A recent study has effectively shown an association between HCM and shorter QT interval, longer PR interval, and J point elevation (mimicking a Brugada syndrome) regardless of the HCM etiology [24]. Brugada-type EKG is associated with increased risk of fatal ventricular arrhythmias and sudden death [25]. Only a few previous case reports studies described ventricular tachycardia and fibrillation in HCM patients [26, 27]. In our study, one patient presented with an ST segment elevation, and another patient (with concomitant hypokalemia) presented with a ventricular tachycardia. The scarcity of severe cardiac rhythm disorder found in our study may be explained by an early ICU admission policy in the two centers and an early treatment of HCM (with a median delay of bisphosphonate therapy on the day of admission).

Beside cardiovascular events, AKI was frequent and often severe (19\% of AKI patients required renal replacement therapy). Multiple mechanisms may be involved in HCM-induced AKI, including a decrease of glomerular ultrafiltration coefficient [28], the induction of nephrogenic diabetes insipidus via down-regulation of aquaporin-2, disruption of countercurrent multiplier system $[29,30]$ and a loop diuretic-like effect [31], that participate to polyuria and volume depletion. Accordingly, almost two-third of HCM-induced AKI patients had a pre-renal AKI phenotype and 11\% where polyuric prior ICU admission. Other factors, such as nephrotoxic drugs, tumor lysis syndrome, and an underlying hematological malignancy with renal involvement have participated to AKI episodes in our study. Our study was underpowered to show an impact of AKI on mortality. However, as small changes in serum creatinine have been shown to be associated with increased mortality [32, 33], prolonged hospital stay, and decrease of complete remission of the underlying malignancy in hematologic patients [34], we believe that prompt treatment of HCM to prevent AKI is of utmost importance in HCM patients.

In multivariate analysis, an underlying solid tumor was independently associated with hospital mortality. One explanation is that HCM is often a late complication in the course of solid tumors appearing in our study in $24 \%$ of cases in metastatic stage. Second, HCM patients with underlying solid tumors experienced more neurological complications. Delirium is known to be associated with longer hospital stay, higher ICU, and hospital mortality $[35,36]$. We then believe that HCM patients with neurological symptoms require aggressive treatment of HCM.

ICU mortality in our cohort was $9.9 \%$, which is consistent with the previous studies [37]. However, in the onco-hematology subgroup, $17.3 \%$ of ICU survivors died during hospitalization, after the correction of 


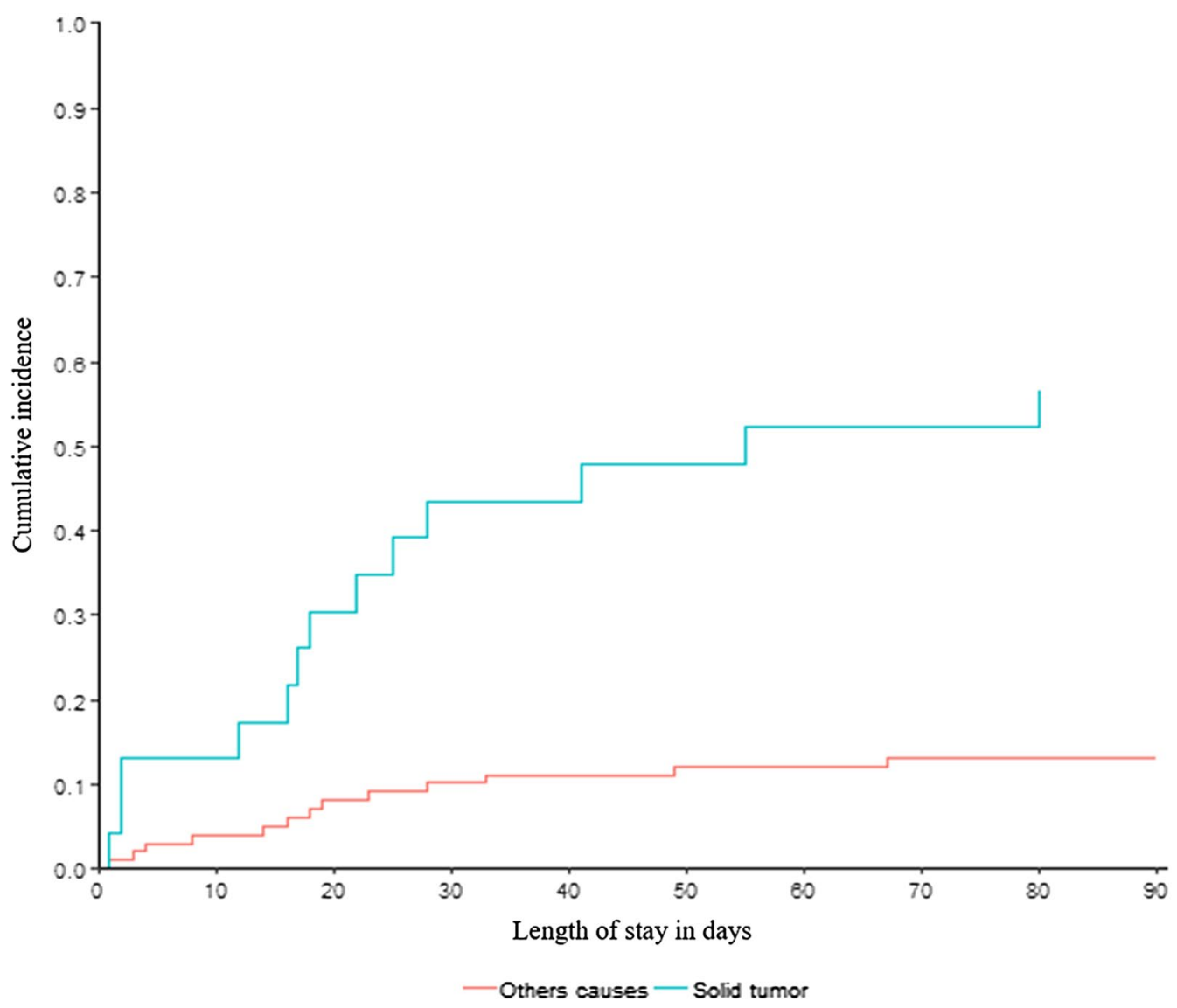

Fig. 2 Cumulative incidence of hospital mortality based on solid tumor status. Blue curve HCM from tumor etiology. Red curve HCM from other causes

Table 6 Multivariate analysis of determinants of hospital mortality

\begin{tabular}{lll}
\hline & OR $(\mathbf{9 5} \% \mathbf{I C})$ & $\boldsymbol{P}$ \\
\hline SAPSII scale score & $1.05(1.01 ; 1.1)$ & 0.03 \\
Age $>60$ years & $2.17(0.65 ; 7.54)$ & 0.21 \\
Etiologies & & \\
$\quad$ Others & 1 & \\
Solid tumors & $13.83(2.24 ; 141.25)$ & 0.01 \\
Endocrinopathies & $1.81(0.07 ; 24.97)$ & 0.67 \\
Hemopathies & $2.76(0.51 ; 24.51)$ & 0.28 \\
Neurological complications & $2.60(0.84 ; 8.36)$ & 0.1 \\
\hline
\end{tabular}

HCM. Causes of death are often multifactorial in these patients and HCM is mainly a marker of an advanced disease. These rates are far lower than usually reported in patients with onco-hematological malignancies hospitalized in ICU. Indeed, a prospective multicentric study grouping 1011 patients with hematological malignancies found an ICU and hospital mortality rate at $27.6 \%$ and $38.3 \%$, respectively [38]. Even worse results were found in a Korean monocentric study gathering onco-hematological patients. ICU and hospital mortality rate were, respectively, $32.2 \%$ and $56 \%$ [39]. This discrepancy is explained by two reasons: first, the nature of ICU admission in our study. While the most common ICU admissions reasons are usually sepsis and acute respiratory failure, the main reason of admission in our study was the HCM itself without a significant rate of multivisceral failure, as suggested by the low median levels of SOFA scores at admission. Second, early ICU admission of these patients allowed prompt HCM aggressive therapy. Indeed, almost all patients received an adequate hyperhydration; $80 \%$ of them receiving bisphosphonate infusion at day 0 . Only the use of bisphosphonate has been linked with a significant decrease of calcemia on day 5 . We believe that this medication should be the cornerstone of the treatment of severe HCM, regardless of renal function. 
Our study has several limitations. First, because of the retrospective design of the study, unidentified confounding factors may have been overlooked in the multivariable analysis. Second, due to the small number of patients in our cohort, our study may have been underpowered to show any relationship between HCMinduced AKI and mortality. Moreover, the results of our multivariate analysis show that our confidence intervals are wide, suggesting statistic instability. Third, the high prevalence of onco-hematological malignancies in our cohort may have introduced selection bias in our results. Indeed, this high prevalence may be explained by the specialized recruitment of onco-hematological patients in one center. However, this is consistent with the previous studies that have found malignancies as the main causes of $\mathrm{HCM}$ in emergency department [40].

\section{Conclusion}

Finally, patients with severe HCM are at high risk of organ failures that are most of the time reversible with the early ICU management. An early aggressive therapy of HCM may prevent these complications, mainly AKI. A special attention should be paid to patients with oncohematological malignancies to detect neurological complications associated with HCM.

Prospective studies are needed to finely evaluate the existence of a threshold of HCM beyond which hospitalization in intensive care is necessary or to identify the most effective treatments.

\section{Supplementary information}

Supplementary information accompanies this paper at https://doi. org/10.1186/s13613-019-0606-8.

Additional file 1: Figure S1. Calcemia ( $\mathrm{mg} / \mathrm{dL}$ ) course between day 0 and day 9. Table S1. Patients characteristics with suspected vitamin D intoxication. Table S2. Extra-renal manifestations. Table S3. Univariate analysis of determinants of complications of HCM. Table S4. Impact of therapies on total calcemia at day 5.

\section{Abbreviations}

AKI: acute kidney injury; CKD: chronic kidney disease; eGFR: estimated glomerular filtration rate; HCM: hypercalcemia; ICU: intensive-care unit; IQR: interquartile range; OR: odds ratio; PTH: parathyroid hormone; PTH-rp: parathyroid hormone-related peptide; RRT: renal replacement therapy; SAPS II: simplified acute physiology score; Scr: serum creatinine; SOFA: sequential organ failure assessment.

\section{Acknowledgements}

Not applicable.

\section{Authors' contributions}

Research idea and study design: CM and LZ; data acquisition: CM; statistical analysis; $A D, C M$, and $L Z$; data analysis and interpretation: $C M$ and $L Z$; supervision or mentorship: LZ, VL, EM, CR, BS, and EA. Each author contributed important intellectual content during manuscript drafting or revision and accepts accountability for the overall work by ensuring that questions pertaining to the accuracy or integrity of any portion of the work are appropriately investigated and resolved. CM and LZ take responsibility that this study has been reported honestly, accurately, and transparently; that no important aspects of the study have been omitted; and that any discrepancies from the study as planned have been explained. All authors read and approved the final manuscript.

\section{Funding \\ None.}

\section{Availability of data and materials}

The data sets used and analyzed during the current study are available from the corresponding author on reasonable request.

\section{Ethics approval and consent to participate}

The study was approved by the ethical committee of the "Société de reanimation de langue française" ( $\left.n^{\circ} 18-34\right)$.

\section{Consent for publication}

Not applicable.

\section{Competing interests}

The authors declare that they have no competing interests.

\section{Author details}

${ }^{1}$ Medical Intensive Care Unit, Saint-Louis Hospital, Assistance Publique-Hopitaux de Paris, Paris Diderot University, Paris, France. ${ }^{2}$ Biostatistics Department, Saint-Louis Hospital, Assistance Publique-Hopitaux de Paris, Paris Diderot University, Paris, France. ${ }^{3}$ Nephrology Department, Tenon Hospital, Assistance Publique-Hopitaux de Paris, Paris Sorbonnes University, Paris, France.

Received: 1 June 2019 Accepted: 13 November 2019

Published online: 27 November 2019

\section{References}

1. Rosner MH, Dalkin AC. Onco-nephrology: the pathophysiology and treatment of malignancy-associated hypercalcemia. Clin J Am Soc Nephrol CJASN. 2012;7(10):1722-9. https://doi.org/10.2215/CJN.02470312.

2. Ziegler R. Hypercalcemic Crisis. J Am Soc Nephrol. 2001;12(suppl 1):S3-9.

3. Wang K, Asinger RW, Marriott HJL. ST-segment elevation in conditions other than acute myocardial infarction. N Engl J Med. 2003;349(22):212835. https://doi.org/10.1056/NEJMra022580.

4. Bai HX, Giefer M, Patel M, Orabi Al, Husain SZ. The association of primary hyperparathyroidism with pancreatitis. J Clin Gastroenterol. 2012;46(8):656-61. https://doi.org/10.1097/MCG.0b013e31825c446c.

5. Chen T-H, Huang C-C, Chang Y-Y, Chen Y-F, Chen W-H, Lai S-L. Vasoconstriction as the etiology of hypercalcemia-induced seizures. Epilepsia. 2004;45(5):551-4. https://doi.org/10.1111/j.0013-9580.2004.57003.x.

6. Egi M, Kim I, Nichol A, et al. lonized calcium concentration and outcome in critical illness. Crit Care Med. 2011;39(2):314-21. https://doi. org/10.1097/CCM.0b013e3181ffe23e.

7. Forster J, Querusio L, Burchard KW, Gann DS. Hypercalcemia in critically ill surgical patients. Ann Surg. 1985;202(4):512-8.

8. Sauter TC, Lindner G, Ahmad SS, et al. Calcium disorders in the emergency department: independent risk factors for mortality. PLoS ONE. 2015;10(7):e0132788. https://doi.org/10.1371/journal.pone.0132788.

9. Gastanaga VM, Schwartzberg LS, Jain RK, et al. Prevalence of hypercalcemia among cancer patients in the United States. Cancer Med. 2016;5(8):2091-100. https://doi.org/10.1002/cam4.749.

10. Jick S, Li L, Gastanaga VM, Liede A. Prevalence of hypercalcemia of malignancy among cancer patients in the UK: analysis of the Clinical Practice Research Datalink database. Cancer Epidemiol. 2015;39(6):901-7. https:// doi.org/10.1016/j.canep.2015.10.012.

11. Taccone FS, Artigas AA, Sprung CL, Moreno R, Sakr Y, Vincent J-L. Characteristics and outcomes of cancer patients in European ICUs. Crit Care Lond Engl. 2009;13(1):R15. https://doi.org/10.1186/cc7713.

12. Massion PB, Dive AM, Doyen C, et al. Prognosis of hematologic malignancies does not predict intensive care unit mortality. Crit Care Med. 
2002;30(10):2260-70. https://doi.org/10.1097/01.CCM.0000030456.11264 .EF.

13. Maier JD, Levine SN. Hypercalcemia in the intensive care unit: a review of pathophysiology, diagnosis, and modern therapy. J Intensive Care Med. 2015;30(5):235-52. https://doi.org/10.1177/0885066613507530.

14. World Health Organization. International statistical classification of diseases and related health problems, 10th revision, Fifth edition, 2016

15. Kellum JA, Lameire N, Aspelin P, et al. Kidney disease: Improving global outcomes (KDIGO) acute kidney injury work group. KDIGO clinical practice guideline for acute kidney injury. Kidney Int Suppl. 2012;2(1):1-138. https://doi.org/10.1038/kisup.2012.1.

16. Bellomo R, Ronco C. Indications and criteria for initiating renal replacement therapy in the intensive care unit. Kidney Int Suppl. 1998;66:S106-9.

17. Stewart AF. Clinical practice. Hypercalcemia associated with cancer. N Engl J Med. 2005;352(4):373-9. https://doi.org/10.1056/nejmcp042806.

18. Teasdale G, Jennett B. Assessment of coma and impaired consciousness. A practical scale. Lancet Lond Engl. 1974;2(7872):81-4.

19. Vincent JL, Moreno R, Takala J, et al. The SOFA (Sepsis-related Organ Failure Assessment) score to describe organ dysfunction/failure On behalf of the Working Group on Sepsis-Related Problems of the European Society of Intensive Care Medicine. Intensive Care Med. 1996;22(7):707-10.

20. Le Gall JR, Lemeshow S, Saulnier F. A new simplified acute physiology score (SAPS II) based on a European/North American multicenter study. JAMA. 1993;270(24):2957-63.

21. Oken MM, Creech RH, Tormey DC, et al. Toxicity and response criteria of the Eastern Cooperative Oncology Group. Am J Clin Oncol. 1982;5(6):649-55

22. Charlson ME, Pompei P, Ales KL, Mackenzie CR. A new method of classifying prognostic comorbidity in longitudinal studies: development and validation. J Chronic Dis. 1987;40(5):373-83.

23. Zhang Z, Xu X, Ni H, Deng H. Predictive value of ionized calcium in critically ill patients: an analysis of a large clinical database MIMIC II. PLoS ONE. 2014;9(4):e95204. https://doi.org/10.1371/journal.pone.0095204.

24. al SK et. High Frequency of Early Repolarization and Brugada-Type Electrocardiograms in Hypercalcemia.-PubMed-NCBI. https://www.ncbi.nIm. nih.gov/pubmed/26263049. Accessed 7 Oct 2018.

25. Zeb M, McKenzie DB, Naheed B, Gazis T, Morgan JM, Staniforth AD. Hypercalcaemia and a Brugada-like ECG: an independent risk factor for fatal arrhythmias. Resuscitation. 2010;81(8):1048-50. https://doi.org/10.1016/j. resuscitation.2010.04.025.

26. Wu L-S, Wu C-T, Hsu L-A, Luqman N, Kuo C-T. Brugada-like electrocardiographic pattern and ventricular fibrillation in a patient with primary hyperparathyroidism. Eur Eur Pacing Arrhythm Card Electrophysiol J Work Groups Card Pacing Arrhythm Card Cell Electrophysiol Eur Soc Cardiol. 2007;9(3):172-4. https://doi.org/10.1093/europace/eum002.

27. Kiewiet RM, Ponssen HH, Janssens ENW, Fels PW. Ventricular fibrillation in hypercalcaemic crisis due to primary hyperparathyroidism. Neth J Med. 2004;62(3):94-6.

28. Marchand GR. Effect of parathyroid hormone on the determinants of glomerular filtration in dogs. Am J Physiol. 1985;248(4 Pt 2):F482-6. https ://doi.org/10.1152/ajprenal.1985.248.4.F482.
29. Sands JM, Flores FX, Kato A, et al. Vasopressin-elicited water and urea permeabilities are altered in IMCD in hypercalcemic rats. Am J Physiol. 1998;274(5 Pt 2):F978-85.

30. Khositseth S, Charngkaew K, Boonkrai C, et al. Hypercalcemia induces targeted autophagic degradation of aquaporin-2 at the onset of nephrogenic diabetes insipidus. Kidney Int. 2017;91(5):1070-87. https://doi. org/10.1016/j.kint.2016.12.005.

31. Hebert SC, Brown EM, Harris HW. Role of the $\mathrm{Ca}(2+)$-sensing receptor in divalent mineral ion homeostasis. J Exp Biol. 1997;200(Pt 2):295-302.

32. Coca SG, Peixoto AJ, Garg AX, Krumholz HM, Parikh CR. The prognostic importance of a small acute decrement in kidney function in hospitalized patients: a systematic review and meta-analysis. Am J Kidney Dis Off J Natl Kidney Found. 2007;50(5):712-20. https://doi.org/10.1053/j. ajkd.2007.07.018.

33. Chertow GM, Burdick E, Honour M, Bonventre JV, Bates DW. Acute kidney injury, mortality, length of stay, and costs in hospitalized patients. J Am Soc Nephrol. 2005;16(11):3365-70. https://doi.org/10.1681/ASN.20040 90740.

34. Canet $\mathrm{E}$, Zafrani L, Lambert J, et al. Acute kidney injury in patients with newly diagnosed high-grade hematological malignancies: impact on remission and survival. PLoS ONE. 2013;8(2):e55870. https://doi. org/10.1371/journal.pone.0055870.

35. Ouimet S, Kavanagh BP, Gottfried SB, Skrobik Y. Incidence, risk factors and consequences of ICU delirium. Intensive Care Med. 2007;33(1):66-73. https://doi.org/10.1007/s00134-006-0399-8.

36. Ely EW, Shintani A, Truman B, et al. Delirium as a predictor of mortality in mechanically ventilated patients in the intensive care unit. JAMA 2004;291(14):1753-62. https://doi.org/10.1001/jama.291.14.1753.

37. Checkley W, Martin GS, Brown SM, et al. Structure, process, and annual ICU mortality across 69 centers: united States Critical IIIness and Injury Trials Group Critical IIIness Outcomes Study. Crit Care Med. 2014:42(2):34456. https://doi.org/10.1097/CCM.0b013e3182a275d7.

38. Azoulay E, Mokart D, Pène F, et al. Outcomes of critically ill patients with hematologic malignancies: prospective multicenter data from France and Belgium-a groupe de recherche respiratoire en réanimation onco-hématologique study. J Clin Oncol Off J Am Soc Clin Oncol. 2013;31(22):28108. https://doi.org/10.1200/JCO.2012.47.2365

39. Lee D-S, Suh GY, Ryu J-A, et al. Effect of early intervention on long-term outcomes of critically ill cancer patients admitted to ICUs. Crit Care Med. 2015;43(7):1439-48. https://doi.org/10.1097/CCM.0000000000000989.

40. Lindner G, Felber R, Schwarz C, et al. Hypercalcemia in the ED: prevalence, etiology, and outcome. Am J Emerg Med. 2013;31(4):657-60. https://doi. org/10.1016/j.ajem.2012.11.010.

\section{Publisher's Note}

Springer Nature remains neutral with regard to jurisdictional claims in published maps and institutional affiliations.

\section{Submit your manuscript to a SpringerOpen ${ }^{\circ}$ journal and benefit from:}

- Convenient online submission

- Rigorous peer review

- Open access: articles freely available online

- High visibility within the field

Retaining the copyright to your article

Submit your next manuscript at springeropen.com 